\title{
History of the development of IS radars and founding of the Institute of Ionosphere in Ukraine
}

\author{
L. Ya. Emelyanov and T. G. Zhivolup \\ Institute of Ionosphere, Kharkiv, Ukraine \\ Correspondence to: L. Ya. Emelyanov (leonid.ya.emelyanov@gmail.com)
}

Received: 10 July 2012 - Revised: 14 January 2013 - Accepted: 30 January 2013 - Published: 25 February 2013

\begin{abstract}
This paper describes the stages of the development of IS radars, the formation and development of the Institute of Ionosphere of the National Academy of Sciences of Ukraine and Ministry of Education and Science, Youth and Sport of Ukraine (IION) from the first steps in the implementation of ionospheric radar equipment near Kharkiv (Kharkov) up to the current state. The paper discusses the main trends in the scientific and technical activities of the Institute, its relations with scientific communities, and demonstrates major scientific achievements.
\end{abstract}

1 The beginning

From the late 1940s until the early 1950s the advances in the development of radiolocation, radio navigation and other branches of radiophysics, radio engineering and radio electronics were gathering momentum. That was strongly dictated by the need to strengthen the USSR defense capability, to move forward with radio electronic industry and to start the pioneering exploration of outer space. These needs lead to the establishment of the Radio Engineering Faculty at the Kharkiv Institute of Electrical Engineering in 1946 (since 1949 - the Kharkiv Polytechnic Institute (KhPI), since 2000 - the National Technical University "Kharkiv Polytechnic Institute" (NTU "KhPI"). The faculty was established at the initiative of Academician A. A. Slutskin and Professor S. Ya. Braude.

The work associated with the studies of the ionosphere was started in 1950s. Specifically, a decision was made to develop the ionospheric station project that was launched under the direction of Prof. S. Ya. Braude.

Researchers and engineers of the Radio Engineering Faculty started the first investigations of the mid-latitude ionosphere over Kharkiv in 1954. In the 1950s, the research group headed by Dr. B. L. Kashcheyev conducted extensive studies on meteor radiolocation. The participation of the scientific staff of the faculty in the ionospheric research during the International Geophysical Year (1957-1958) was highly important for the formation and development of the meteor radiolocation scientific school in the USSR.

\section{The 1960s - The Research Laboratory of lonosphere}

The Research Laboratory of Ionosphere (RLI) was established at the Radio Engineering Faculty of KhPI in 1963. Dr. Vitaly I. Taran headed the Laboratory. RLI focused on exploring the ionosphere by using a novel, promising technique, i.e. the method of incoherent scatter (IS) of radio waves.

Similar work on the ionospheric studies had been carried out in the USA. Pioneering papers on the theory and practice of the IS technique were published by Gordon (1958), Bowles (1958), Fejer (1960, 1961), Hagfors (1961, 1962) and others.

The construction of a unique special-purpose Observatory with the reference-class scientific instrumentation (the only IS radar in the Soviet Union) was started near the town of Zmiyiv (Zmiev), about $50 \mathrm{~km}$ from Kharkiv, $49.6^{\circ} \mathrm{N}$, $36.3^{\circ} \mathrm{E}$. The primary goal of this stage of the project was to prepare the infrastructure capable of supporting the experimental research facility - to construct the buildings that could accommodate the appropriate elements of radar equipment, a water tower along with hydraulic engineering installations, 


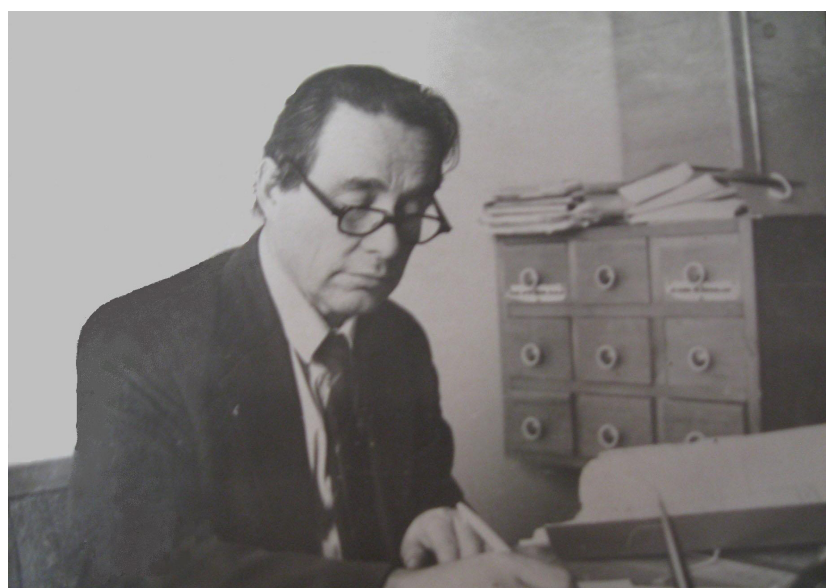

Figure 1. Dr. V. I. Taran.

as well as the powerful electric power supply. Many organizations got involved in this dramatically important project.

In accordance with the decision of the Council of Ministers of the USSR the radio engineering equipment, including the core facilities such as special radars, was transferred to RLI. Some of the items were mainly the components of radar transmitters and receivers that had been previously removed from service and had to be repurposed for scientific use. Dozens of RLI staff members were involved in dismantling, transporting and installing the equipment. A number of radar units, which were specific to implementation of the IS method, were designed and manufactured by RLI personnel.

From the outset, the whole RLI team focused on providing this unique experimental facility with the necessary equipment. The most critical share of work was performed by leading experts such as I. N. Presnyakov, E. V. Rogozhkin, V. I. Golovin, V. I. Liokumovich, E. I. Grigorenko, A. A. Solyanik, S. D. Andrenko, and A. S. Efremenko.

For many years dozens of scientists, engineers and technicians had to be engaged in the crucial part of work on designing and developing IS radars as powerful tools for probing the ionosphere, dedicated data processing systems, highefficiency techniques for ionospheric sounding, IS signal reception and processing.

In 1968 an automatic ionospheric station (ionosonde) was put into operation. Within subsequent years its equipment was upgraded and it stayed in operational service up to the period of the 1980s.

\section{The 1970s}

In 1971 the Department of Radio Electronics was established at KhPI as a result of V. I. Taran's initiative. Dr. V. I. Taran became the head of the Department. The Research Laboratory of Ionosphere was transformed into a Research Laboratory of the Department of Radio Electronics.

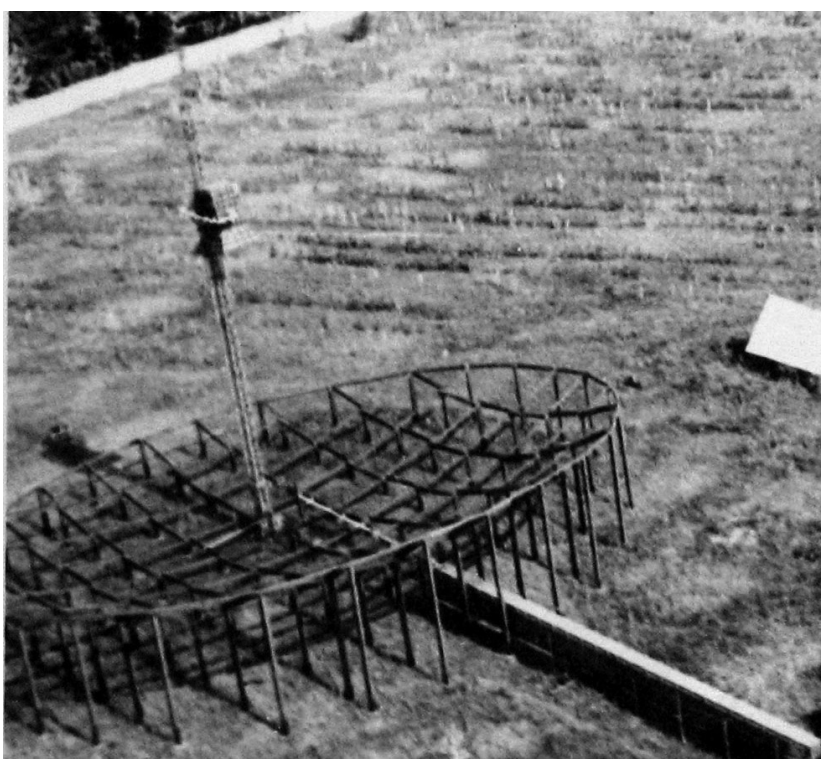

Figure 2. The first parabolic antenna $30 \mathrm{~m}$ in diameter.

The first IS technique results were obtained in 1972 by using a radar equipped with a fixed $30-\mathrm{m}$ parabolic antenna, industrial transmitter and additional facilities (specially designed under the leadership of I. N. Presnyakov): receiver, power meter and spectrum analyzer. The radar operating frequency was about $150 \mathrm{MHz}$, the peak power and pulse duration were about $1 \mathrm{MW}$ and $1 \mathrm{~ms}$, respectively. The low-noise tube amplifier was used as input stage of the receiver. The spectrum analyzer had 24 of $200-\mathrm{Hz}$ bandwidth frequency channels. Ionospheric sounding was conducted in a linear polarization mode.

Subsequently the radar was significantly improved. The KhPI pilot plant, along with a number of design organizations of the Soviet Union, manufactured a unique 100-m dual-reflector parabolic antenna (Taran, 1976). In Europe, it was the largest, vertically directed antenna (with beam width about $1^{\circ}$ ) and became the main tool for studying the ionosphere. It was made according to Cassegrain configuration. The antenna allowed for the transmitting and receiving of signals with the circular and linear polarization. The isolation between the receiving and transmitting channels in two waveguide feeder lines was ensured by using the waveguideslot antenna switches.

A new, more reliable and sensitive radio receiver was implemented during this period. It had the input low-noise nonregenerative parametric amplifier with noise temperature of about $100 \mathrm{~K}$. In fact, the VHF IS radar was developed on the basis of a powerful transmitter, a new antenna and a new radio receiver. The radar enabled studies of the ionosphere in the altitude range of $100-1000 \mathrm{~km}$ with systematic measurements of the basic ionospheric parameters (electron density, electron and ion temperatures, velocity of the ionospheric plasma, relative density of molecular and atomic 


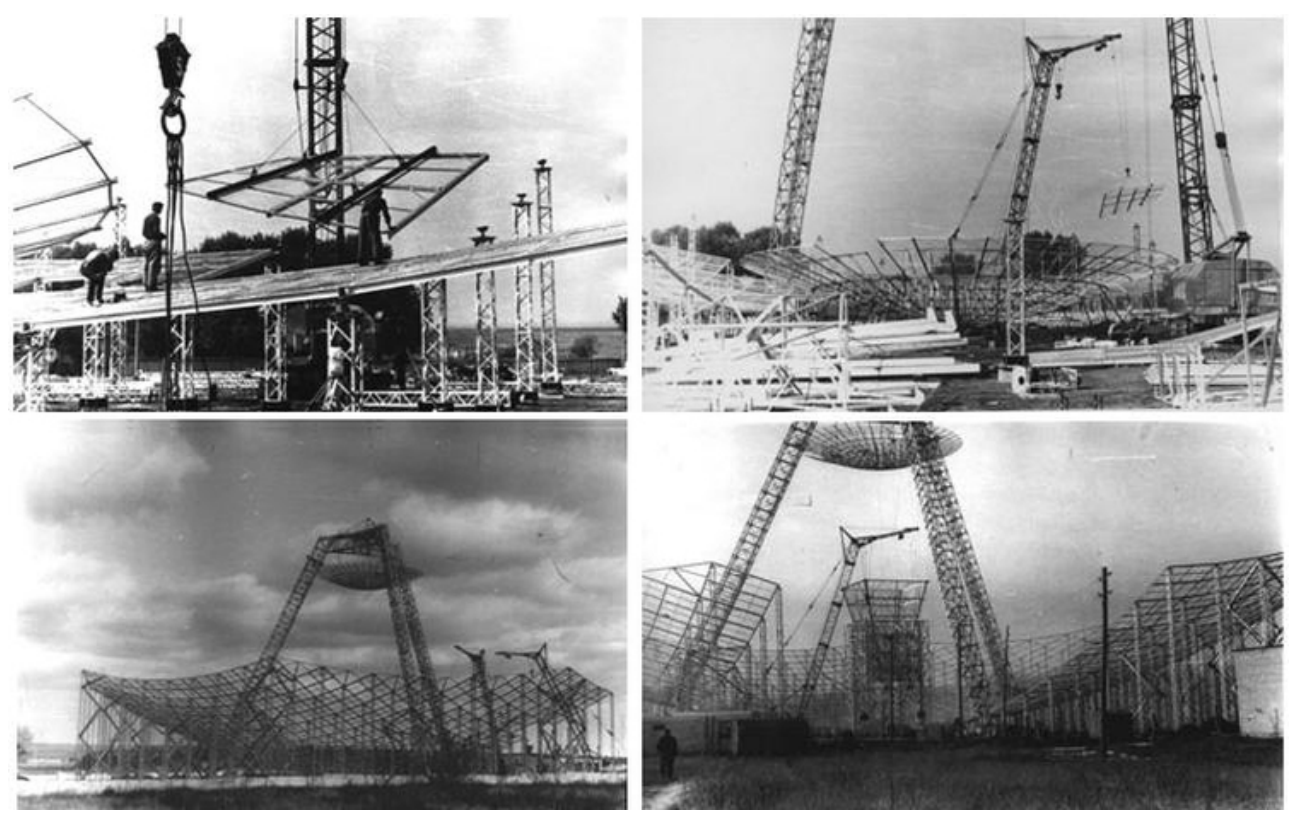

Figure 3. Construction stages of the 100-m-diameter parabolic antenna.

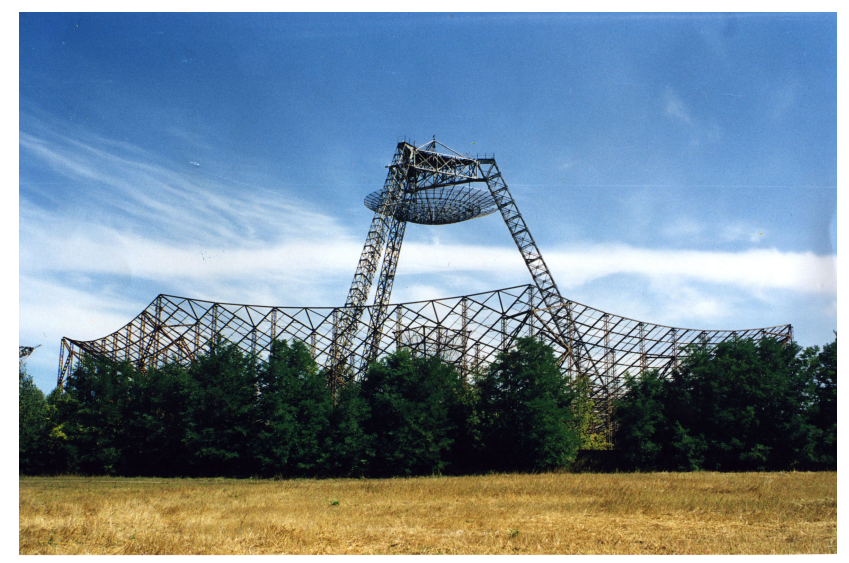

Figure 4. The IS radar with the 100-m parabolic antenna.

ions) (Taran, 1976). Simultaneous observations of these parameters was a unique advantage of IS technique.

Starting in 1975, regular studies of the ionosphere were performed using a correlator developed and manufactured by a team of specialists headed by E. V. Rogozhkin and F. A. Maenko (Rogozhkin et al., 1979). The correlator included the analog-to-digital converter, the arithmetic unit (the shift registers, the digital multipliers and adders), the magnetic-core memory, the output devices, and the control unit. Work on the correlator development continued from 1968. This correlator had been the "heart" of the IS radar for many years. It acted as a processing device and as the IS radar synchronizer until the end of 1980 s, when it was replaced by a new correlator combined with a personal computer (PC). The correlator was continuously upgraded as radar equipment and techniques for measuring ionospheric parameters became more mature. The principle of its operation was proposed by E. V. Rogozhkin and was based on determining the values of the correlation function of IS signal at an intermediate frequency that coincides with its envelope due to the choice of the appropriate lags (Rogozhkin, 1979). Such a correlator turned out to use a smaller number of hardware components than ordinary similar hardware and to be simpler in its manufacturing without the loss of the signal processing quality.

A group led by V. N. Golovin made a great contribution to the modernization of the IS radar radio transmitting facilities (Golovin et al., 1979a).

Due to the IS radar modernization, the following basic modes were introduced and employed (Golovin et al., 1979b):

- sounding with a pulse of $800 \mu$ s length (to measure the parameters of the upper ionosphere and the ionosphere at the altitudes near the peak of the ionospheric $F$ layer);

- sounding with a cyclic sequence of double pulses (150 $\mu$ s length) with a variable delay between pulses from one period of sounding to another. Every delay was equal to the respective lag of measured correlation function. This mode was used for measurement of the ionospheric parameters at altitudes of $100-550 \mathrm{~km}$ with better altitude resolution;

- sounding with a single pulse of $150 \mu$ s length at a higher repetition frequency for study of fast processes in the ionosphere; 


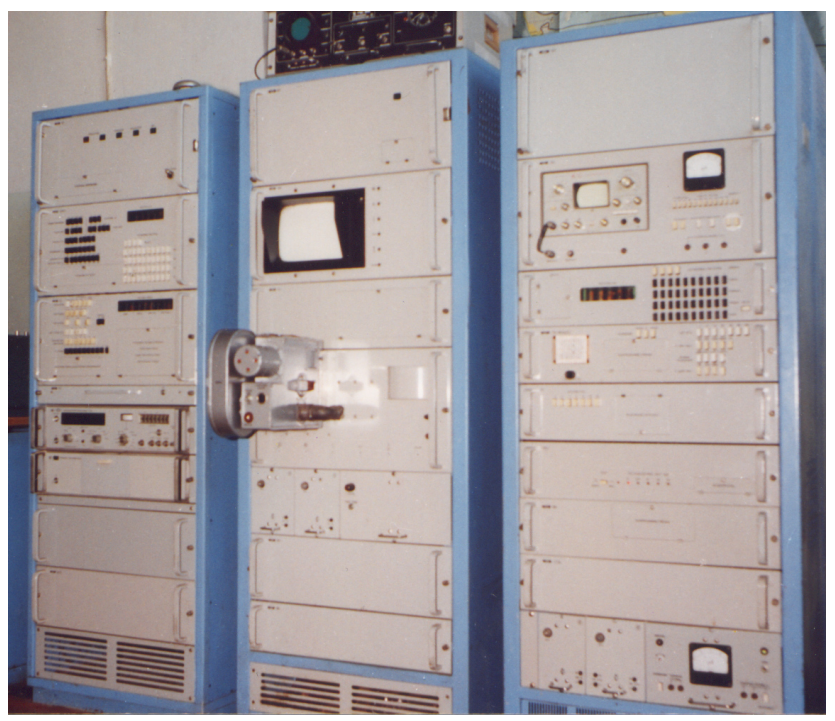

Figure 5. Ionosonde "Basis".

- sounding with a signal of $150 \mu$ s length with linear polarization (in contrast to circular polarization of previous modes) to determine the electron density using the Faraday effect.

Ionospheric parameters were usually measured using signals with circular polarization to avoid Faraday fading IS echoes.

A number of experiments to determine the electron density using the Faraday effect (with linearly polarized transmitting and receiving signals) was conducted at the Kharkiv IS radar. In the framework of such experiments, E. I. Grigorenko improved the method of processing the IS signals that were received by two orthogonal antenna dipoles, and analyzed the obtained results (Grigorenko, 1979).

In 1977 a group led by N. P. Maglevanny conducted the first experiments with coded signals, which allowed for the study of the fine structure of the lower ionosphere (Maglevanny et al., 1979).

\section{Development of the Kharkiv incoherent scatter radar in the $1980 \mathrm{~s}$}

Starting in the 1970s, the IS radar was used to study the ionospheric effects associated with powerful explosions and spacecraft launches (Taran et al., 1985). The ionospheric disturbances caused by these anthropogenic factors were observed at distances up to a few thousand kilometers from the energy source.

By 1980, the Kharkiv Computer Center for the IS data processing was created on the basis of SM-4 (PDP-11 ana$\log$ ) computers. The center offered the possibility for any researcher to solve direct and inverse problems of ionospheric sounding and to develop theoretical models. These comput-

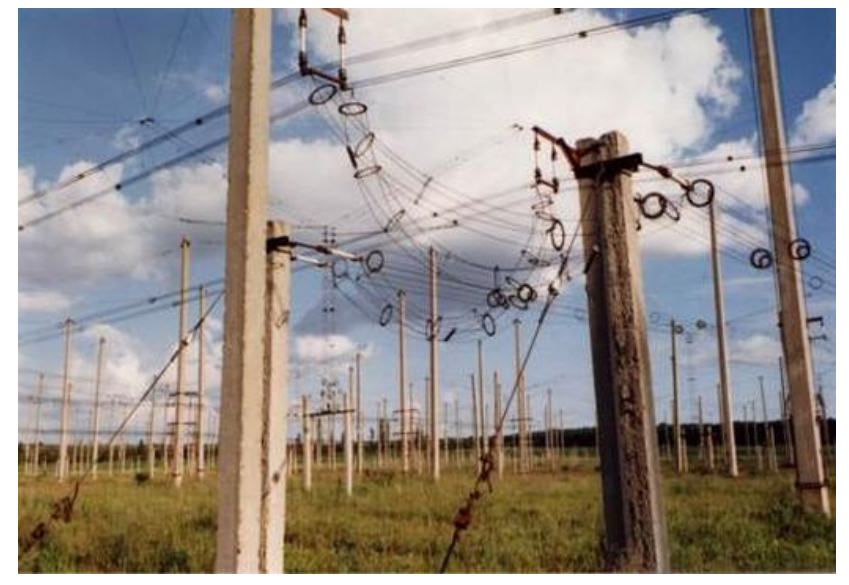

Figure 6. Elements of the heating facility antenna.

ers were used to develop a data bank of IS radar measurements saving collected data on magnetic media.

In 1983 the Research Laboratory of the Department of Radio Electronics gained the status of the Separate Design Department for Radiophysical Studies of Ionosphere (SDDRSI).

In the same year, SDDRSI organized the All-USSR Scientific-Technical Conference "Theory and Practice of Application of the Incoherent Scatter of Radio Waves Method" in the Crimea. The possibility of the IS method and the experimental results obtained at the Kharkiv IS radar were widely demonstrated at this conference ("Theory and Practice...", Abstracts, 1983). Prof. G. A. Zherebtsov, Dr. L. M. Erukhimov, Dr. A. V. Mikhailov, Dr. Y. K. Chasovitin, and other eminent Soviet scientists participated and made presentations at the conference. Representatives of the Soviet Union scientific institutions took a great interest in the capabilities of the unique (in the USSR) Kharkiv IS radar facility and the results obtained with this radar. This interest resulted in an active collaboration between Kharkiv scientists and colleagues from the Institute of Applied Geophysics (Moscow) and the Siberian Branch of the Institute of Terrestrial Magnetism, Ionosphere and Radio Wave Propagation of the Academy of Sciences of the USSR (Irkutsk). The results of the radar facility development and the progress in study of the ionosphere by the Kharkiv IS radar promoted later the development of the Irkutsk IS radar.

In 1985 the ionosonde "Basis" was put into operation. It is currently used for the calibration of the vertical profile of electron density obtained by IS radar as well as for the ionospheric studies by the vertical sounding method.

The installation and the implementation of HF heating facility with $300 \times 300 \mathrm{~m}^{2}$ phased array antenna was carried out in the first half of the 1980s (Bogdan et al., 1986). In 1985 the first experiments to study ionospheric plasma disturbances due to high-power HF modification of the ionosphere (with 


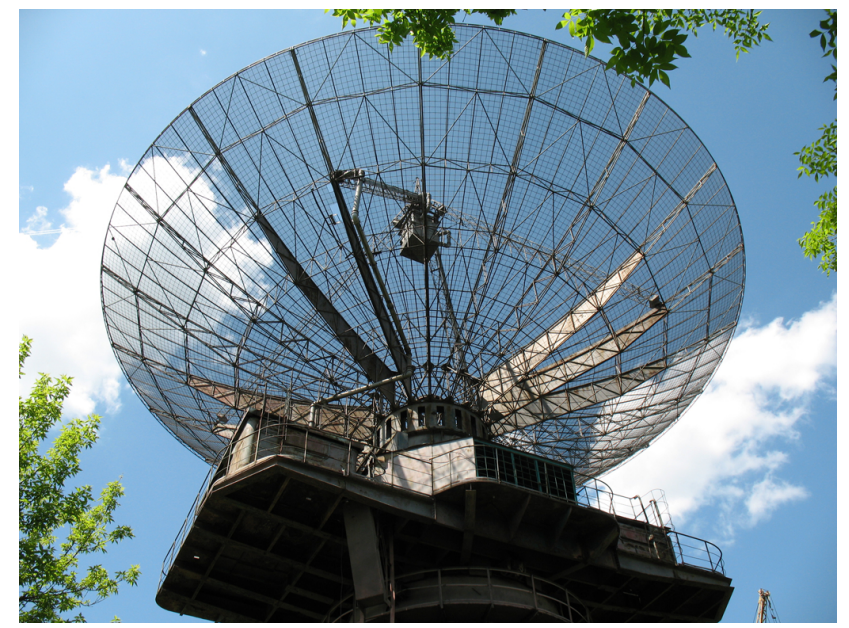

Figure 7. The fully steerable 25-m-diameter antenna.

introduced to that time HF heating facility) were conducted (Rogozhkin et al., 1987).

In 1986-1989, a group led by E. V. Rogozhkin and V. A. Pulyaev developed a multifunctional correlator/spectrum analyzer named "SKIF". It was built on the basis of the developed specialized digital devices and personal computers that became available at that time (Rogozhkin et al., 1989). "SKIF" was able to simultaneously determine up to 40 values of the correlation function or spectrum of IS signal. Its performance was up to $300 \times 10^{6}$ flops.

A group under the leadership of L. Ya. Emelyanov developed and introduced a versatile multi-channel receiving and driving system (Emelyanov, 1993). This system significantly expanded the capabilities of the IS radar and allowed for use of composite signals with the frequency and phase manipulation. The system provided the possibility to simultaneously determine the ion and two electron components of the IS signal spectrum, to form a composite sounding signal, to select and transform the IS echo signals from composite sounding signal elements to the same intermediate frequency for correlation processing. In addition, it enabled the simultaneous reception of signals with orthogonal linear or circular (right and left) polarizations, or enabled simultaneous operation with the zenith-directed and steerable antennas at different carrier frequencies to avoid interference. Sounding signal of transmitter and clock signal for the correlator were formed from the receiver heterodyne signals. Thereby the coherent structure of the radar systems were able to determine the ionospheric plasma drift velocity from the Doppler shift of the IS signal spectrum.

The radio transmitting facility was cardinally upgraded by a team led by A. N. Smirnov. A new transmitter was equipped with more modern components. In particular, the thyristors were used in the modulators instead of gas-filled thyratrons. The metal-ceramic tubes were used in power amplifiers instead of metal-glass ones. The efficiency of the transmitter,

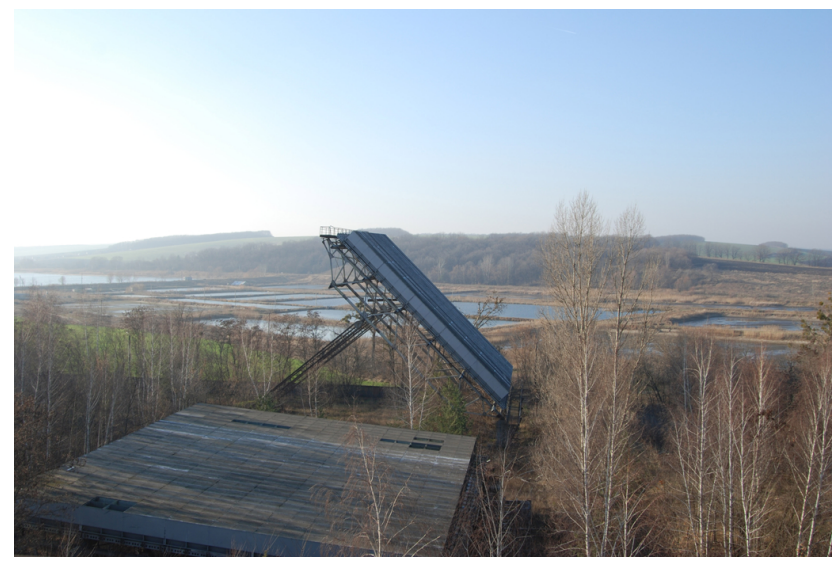

Figure 8. The UHF IS radar antenna.

stability and reliability of its operation increased. However, a new radio transmitter was only capable to form sounding radio pulses with a repetition frequency of $24.4 \mathrm{~Hz}$.

The Department scientists presented their research results and achievements in developing the radar facility and measurement techniques at many topical conferences that were held in the Soviet Union.

In 1987 SDDRSI organized the All-USSR Conference "Theory and Practice of the Incoherent Scatter Method Application to Study the Ionosphere". Well-known geophysicist Prof. A. D. Danilov and Prof. S. A. Pulinets, the Deputy Director of the Institute of Terrestrial Magnetism, Ionosphere and Radio Wave Propagation (IZMIRAN) of the Academy of Sciences of the USSR, and others attended. The problems related to the instrumental and methodical features of IS radars, the results of measurements by IS technique and the use of the IS data for ionospheric models were discussed in multiple presentations ("Theory and Practice...", Abstracts, 1987). In conclusion of the conference, the use of the Kharkiv IS radar data for improvement of ionospheric models, particularly IRI model, was recommended.

In 1989 the fully steerable parabolic antenna, $25 \mathrm{~m}$ in diameter, was installed in the observatory. The first unique results of spatial study of the surrounding ionosphere by IS method were obtained with this antenna (Chepurnoy, 1990).

In the 1980s a group led by S. V. Chernyaev introduced the UHF IS radar for the study of the fine structure of the lower ionosphere (Chernyaev, 1979).

Specialized processing systems of a new generation (for that time) for UHF and VHF radars were developed and introduced by a team headed by V. N. Lysenko (Lysenko and Kochergin, 1993). Mr. Lysenko also developed software for primary (real-time) processing of the IS signal and calculation of the ionospheric parameters (Lysenko, 1999; Lysenko, 2002).

During the 1970-1980s computing aids for the secondary digital processing of data obtained by the IS radar were intensively developed. At each stage of development, 
the most current available computers were used: "Mir2 " (12000 flops), "5E73" (2.2 × $10^{5}$ flops), "SM-4" $(8 \times$ $10^{5}$ flops), ES-1045 (analog of IBM System/370, $8 \times$ $10^{5}$ flops), and, finally, personal computers. "5E73" was a unique computer that specialized in processing radar data with programming in digital codes. These computers were used for the primary (real-time) processing of the experimental data at the IS radar. Basic calculations and theoretical ionosphere modeling were done at the Computer Center in Kharkiv. The new ionospheric data processing programs were developed.

By the end of 1980s the first in the Soviet Union empirical model of the F-region ionosphere above Kharkiv was developed based on experimental IS radar data. This model included dependency on season, solar activity, local time, and altitude (Grigorenko, 1991).

In 1989 a group of SDDRSI scientists was awarded the Prize of the Council of Ministers of the USSR for progress in scientific research of the ionosphere by Kharkiv IS radar. This group included Prof. V. I. Taran (Department head), Dr. E. V. Rogozhkin, E. I. Grigorenko, A. N. Gridin, and A. N. Smirnov.

In 1990 the Separate Design Department for Radiophysical Studies of Ionosphere was renamed into the Special Design Department for Radiophysical Studies of Ionosphere (SpDDRSI).

In October 1990 SpDDRSI organized the 16th All-USSR Conference on Propagation of Radio Waves. This conference was held in Kharkiv. The well-known Soviet scientists, namely, Prof. G. S. Ivanov-Kholodny, Dr. A. V. Mikhailov, Prof. V. V. Migulin, Corresponding Member of the Academy of Sciences of the USSR, made presentations at the conference. The SpDDRSI scientists presented the results of studies of the ionosphere using the IS method. In particular, they presented information about new hardware development of the Kharkiv IS VHF radars (with fixed and steerable antennas) and IS UHF radar, accuracy measurements of ionospheric parameters by the IS technique, and studies of the ionosphere in quiet and disturbed conditions, including the artificial ionospheric modification by high-power HF radio waves (Proceedings of the 16th All-USSR Conference on Propagation of Radio Waves, 1990).

After the conference in 1990, SpDDRSI started a close scientific cooperation with the IZMIRAN (Troitsk, Moscow region). T. G. Zhivolup, along with Prof. G. S. IvanovKholodny, developed an empirical model for the ionospheric E-layer peak height. L. P. Goncharenko and Dr. V. V. Vaskov studied ionospheric effects arising from the influence of highpower HF radio transmission and reported significant perturbations in the F-region electron density (Andreyev et al., 1991; Goncharenko et al., 1991; Taran et al., 1993).

\section{Institute of Ionosphere}

The Institute of Ionosphere was established on 17 April 1991, in accordance with the decision of the Council of Ministers of Ukraine. The Institute of Ionosphere (IION) has evolved from the Research Laboratory of Ionosphere, Separate Design Department and (later) the Special Design Department for Radiophysical Studies of Ionosphere. IION began operating under double subordination of the National Academy of Sciences of Ukraine and the Ministry of Education and Science of Ukraine. Prof. V. I. Taran was appointed the director of IION.

Since the establishment of IION, the development of its experimental base, particularly, the radio transmitting, the radio receiving, and the data processing systems, was further continued and the data processing methods were improved.

After the break-up of the Soviet Union, Ukraine went through hard times, when even major industrial enterprises were shut down and an outflow of scientists began going abroad. The great accomplishment of Prof. V. I. Taran, Director of IION, was that he managed to preserve the technical and scientific base of the institute from being disintegrated and to hold the key qualified personnel together during these trying times. Moreover, ionospheric studies were not stopped in the ionospheric observatory of IION.

During many years before and after the formation of IION, A. N. Gridin, Deputy Director of the Institute, performed the extraordinarily important and necessary work on planning the IION activities, establishing relationships with customers, negotiating contracts, and coordinating the cooperation with external scientific, military, construction and mounting organizations. It was precisely due to his extraordinary efforts that during those times the Institute was well equipped with up-to-date radar equipment and measuring instruments, and the research and development efforts successfully continued.

In 1990s the new generation of software for processing the IS radar data was developed. This set of software included modern tendencies in the IS method and fully explored capabilities of personal computers that became available at that time. V. N. Lysenko and V. A. Pulyayev were the main developers of these programs.

In November 1991 IION scientists V. N. Lysenko and L. P. Goncharenko participated in the 3rd URSI Symposium (Suzdal, Russia) on the modification of the ionosphere by powerful radio waves (Andreyev et al., 1991). At this meeting they met the American scientists that were engaged in the studies of the ionosphere by the IS method, in particular, Dr. John Foster, Associate Director of Haystack Observatory of the Massachusetts Institute of Technology.

In 1991 a regular cooperation was started between IION and American scientists from the Haystack Observatory, Massachusetts Institute of Technology. In May 1992, a group of US scientists, led by Dr. John Foster, visited IION and its observatory. Scientists of IION were invited to the USA 


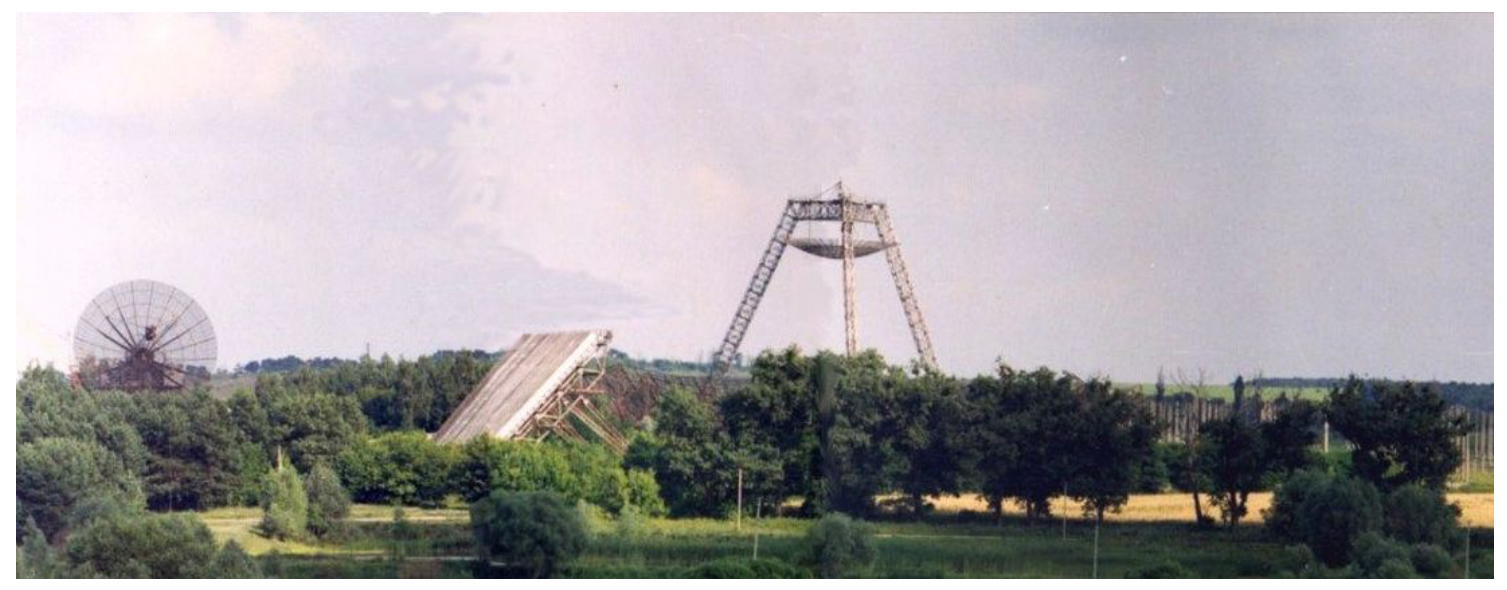

Figure 9. The Observatory of IION.

for joint studies. V. N. Lysenko visited and worked at the Haystack Observatory in 1993.

From October 1994 to January 1995 Prof. V. I. Taran, Dr. E. V. Rogozhkin, and researcher L. P. Goncharenko worked at the Haystack Observatory of the Massachusetts Institute of Technology and at the Arecibo Observatory of Cornell University (Puerto Rico, USA). In January 1995, the presentation of IION was made at the headquarters of the US National Science Foundation in Washington, D.C.

In 1993 T. G. Zhivolup presented an empiric E-Layer Peak Height Model based on the data of the Kharkiv IS radar at IZMIRAN. This model was used for improvements of the International Reference Ionosphere (IRI) Model (IvanovKholodny et al., 1998).

Starting in 1994, IION began a cooperation with the National Space Agency of Ukraine. The agency has allocated substantial funds for the IION IS radar. This allowed regular operations of the IS radar, measurements of ionospheric parameters, maintenance of the IS radar equipment and implementation of some upgrades.

In August 1995 the Meeting of the URSI Incoherent Scatter Radar Working Group was held in IION. Leading Russian scientists Dr. A. V. Mikhailov, Dr. A. V. Tashchilin, the leading US scientists on study of the ionosphere by the IS method Dr. J. Foster, Dr. J. Kelly, Dr. S. Gonzales, and scientists of IION participated in the working group. As a result, researchers decided to cooperate in the study of light ions in the upper ionosphere using the Kharkiv and the Millstone Hill IS radars.

From 1996 the institute began to study of ionospheric light ions variations. A group led by L. Ya. Emelyanov created and implemented a new receiver with an increased sensitivity and stability of its parameters customized for this work (Emelyanov, 1999). The input amplifier was made on the low-noise transistors and coaxial quarter-wave resonator. It still operates and provides sufficient sensitivity, selectivity and reliability. V. A. Pulyayev improved the ionospheric data processing software to account for the light ions. E. I. Grigorenko made a significant contribution to the study of the ion composition in the upper ionosphere (Taran and Grigorenko, 2002a, b).

In 1998 and 1999 IION examined the variations of light ions of helium and hydrogen under the contract with the Massachusetts Institute of Technology in the framework of the Grant from the National Science Foundation, USA (Erickson et al., 1999).

Ionospheric studies that were carried out jointly with Arecibo and Haystack Observatories from 1996 (according to the International Geophysical Calendar) provided information on longitudinal and latitudinal variations of hydrogen ion density.

In 1999 Dr. V. A. Pulyayev visited the Haystack Observatory of the Massachusetts Institute of Technology and the National Center for Atmospheric Research in Boulder, Colorado, USA. At the international meeting on the CEDAR program in Boulder, Dr. V. A. Pulyayev presented data obtained at the Kharkiv IS radar and compared these data with the Millstone Hill IS radar data. His reports described the IION activities, which were positively received by leading international scientists who expressed strong interest in the Kharkiv IS radar observations. The subsequent collaborations incorporated Kharkiv IS radar data in various studies that included the global network of the IS radars and increased the understanding of the latitudinal, longitudinal, and local time effects in the ionospheric plasma (Mishin et al., 2002; Goncharenko et al., 2005).

\section{The Institute of Ionosphere in the 2000s}

Early in the 2000s IION developed and introduced the new signal processing unit that allowed to increase accuracy of the ionospheric parameters measurement (Lysenko et al., 2004). It was a 4-channel programmable correlator, which included the multi-channel analog-to-digital converter (ADC), 


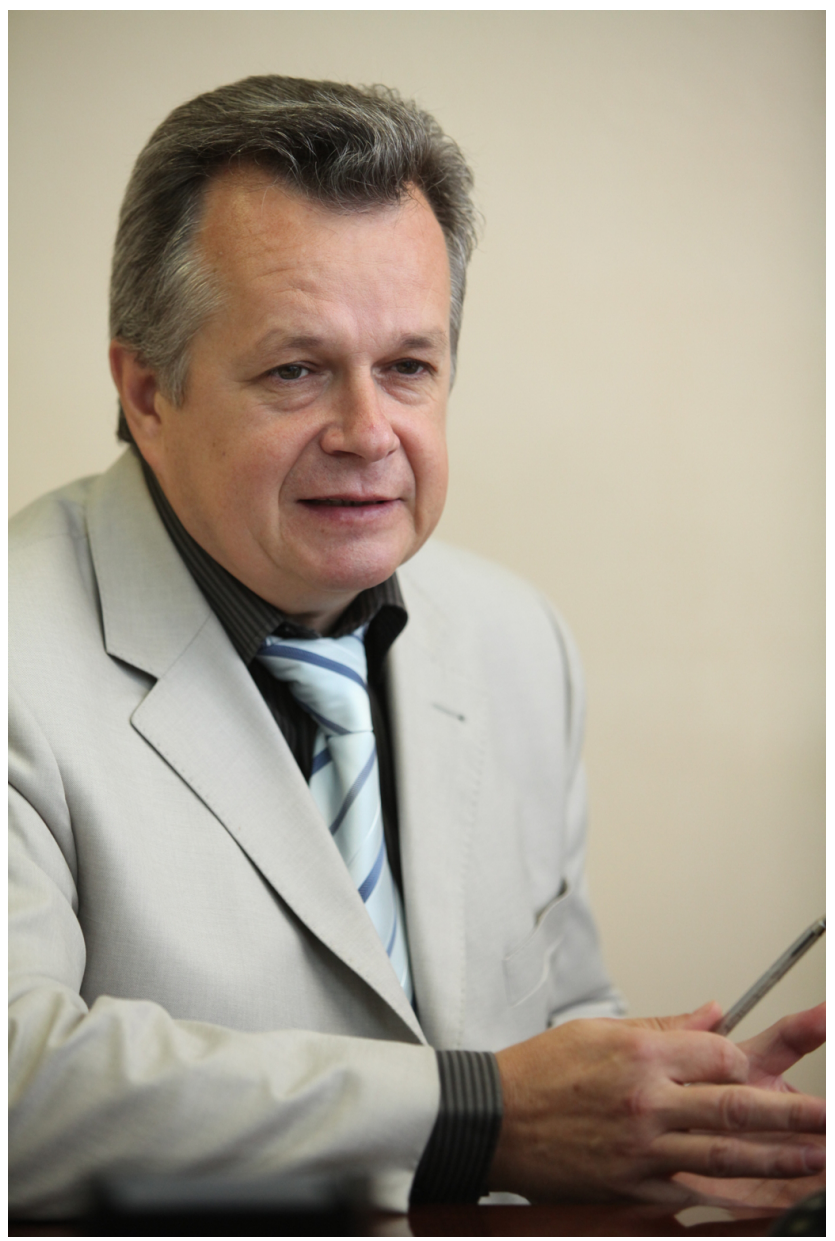

Figure 10. Prof. I. F. Domnin.

PC with a clock frequency of $800 \mathrm{MHz}$, the parallel ADC-PC interface, and synchronizer.

Since the beginning of the 2000s the studies of impact of geospace storms, solar eclipses and the effects related to the launching of ballistic rockets on the ionosphere were considerably intensified in IION (Taran, 2001; Taran et al., 2001). IION also continued further development of the regional ionospheric model (Grigorenko et al., 2001).

In 2001 the ionospheric observatory of IION, called "Ionospheric Sounder", was recognized as an Object of the National Property of Ukraine.

In 2003 Chairman of the EISCAT Scientific Advisory Committee Prof. P. J. S. Williams, University of Wales, UK, visited IION and its ionospheric observatory. This visit included numerous discussions on ionosphere studies by the IS technique.

In 2009 Prof. Igor F. Domnin became the Director of IION. He continues further efforts to improve the scientific and experimental base of the institute, and to develop the cooperation with the national and international scientific communities.
In December 2010 Director of EISCAT Dr. E. Turunen, Prof. A. Brekke and Dr. K. Kauristie visited IION and its ionospheric observatory. This visit included a seminar where the research scientists presented achievements of the Institute in studies of the mid-latitude ionosphere over Ukraine. The visiting scientists highly appreciated the experimental facilities and the scientific achievements of IION.

Overall, Kharkiv IS radar obtained a large amount of experimental data during more than three cycles of solar activity.

At present, the VHF IS radar, with its 100 -m zenith pointing parabolic antenna and vertical sounding ionosonde, are both operating actively in the ionospheric observatory. The research group periodically conducts experiments with the second VHF IS radar with the fully steerable $25-\mathrm{m}$ parabolic antenna. However, the HF ionospheric heating facility with a wide-band $300 \times 300-\mathrm{m}^{2}$ antenna requires major overhaul.

The main parameters of IS radar at present are as follows: the frequency is about $158 \mathrm{MHz}$, the effective aperture of the 100 -m zenith pointing parabolic antenna is about $3700 \mathrm{~m}^{2}$, the two-way half-power antenna beam width is close to $1^{\circ}$, the pulse power of the transmitter is up to $3.6 \mathrm{MW}$ and and the average power is $100 \mathrm{~kW}$, pulse repetition frequency is $24.4 \mathrm{~Hz}$, and the polarization is circular. The noise temperature of the receiver is $120 \mathrm{~K}$ and the receiver bandwidth is $11-19 \mathrm{kHz}$. The effective noise temperature of the system is 470-980 K.

The main mode of the IS radar operation is radio sounding of the ionosphere, using composite two-frequency radio pulse, where the first element has a pulse length of $650 \mu \mathrm{s}$ (the carrier frequency $f_{0}=158 \mathrm{MHz}$ ) and the second element has the pulse length of $130 \mu$ s (the frequency $\left.f_{1}=(158+0.1) \mathrm{MHz}\right)$. As a result of the receiving and processing of the first signal element scattered by the ionosphere, the electron density, the electron and ion temperatures, the vertical component of the plasma velocity, and the ion composition are measured for the altitudes near the peak of the ionospheric F layer and in the upper ionosphere. The height resolution for the first pulse element is about $120 \mathrm{~km}$. The return signal from the second pulse element enables a determination of the altitude profile of the IS signal power at the altitudes of 100 to $550 \mathrm{~km}$, with the height resolution of $20 \mathrm{~km}$ to correct the altitude electron density profile after the first wider pulse.

IION provides gradual upgrades of the ionospheric observatory equipment within available funding and regular ionospheric measurements. Specifically, new fully programmable correlators with ADC and the modern high-performance PC are being introduced. The Institute also continues further development of software for ionosphere parameters determination and improvement of the IION database (Pulyaev et al., 2011).

The research activity of the institute includes a broad spectrum of research topics devoted to the mid-latitude ionosphere. The model of the mid-latitude ionosphere CERIM 
IION (Central Europe Regional Ionospheric Model) was developed using the Kharkiv IS radar data obtained over a period of more than two cycles of solar activity (from 1986 to 2011) (Lyashenko et al., 2011). A large variety of studies addressed different types of ionospheric perturbations, the ionospheric plasma dynamics in general (Yemelyanov and Dzyubanov, 2007; Domnin et al., 2012a), and the wave disturbances in the ionosphere caused by the solar terminator (Burmaka and Chernogor, 2012), by the launches of rockets (Burmaka and Chernogor, 2009), and by the effect of high-power HF radio transmission on the ionospheric plasma (Burmaka et al., 2009). The institute also continues to study the response of the ionosphere to geomagnetic storms (Grigorenko et al., 2007; Chernogor et al., 2012; Domnin et al., 2011) and solar eclipses (Emelyanov et al., 2009; Chernogor et al., 2011; Domnin et al., 2012a). A model of ion composition of the topside ionosphere over Kharkiv, Ukraine, is currently under development (Kotov and Chernogor, 2011).

Over the last decade, the cooperation with national and international research communities has been successfully developed.

In 2010-2012 the wave processes in the ionosphere caused by powerful HF radio transmission were investigated jointly with the Radiophysical Research Institute (Nizhny Novgorod) (Domnin et al., 2012b).

The scientific results are also regularly presented at topical conferences, symposia and seminars at many international forums. IION coordinates its activity with foreign scientific institutions that are actively involved in ionospheric studies.

Acknowledgements. We thank the referees, Risto Pellinen and Larisa Goncharenko for their corrections, valuable comments and suggestions.

Edited by: R. J. Pellinen

Reviewed by: A. Brekke and two anonymous referees

\section{References}

Andreyev, A. E, Bogovsky, V. K., Vaskov, V. V., Gershtein, L. Ya, Goncharenko, L. P., Lysenko, V. N., Maglevanny, N. P., and Taran, V. I.: The first observations of artificially enhanced ion and plasma lines in Kharkov, Proceedings of the III Suzdal URSI symposium on the modification of the ionosphere by powerful radio waves, Moscow, IZMIRAN, p. 119, 1991 (in Russian).

Bogdan, A. P., Bogovsky, V. K., and Divavin, V. V.: High-frequency heating facility, Bulletin of the Kharkov Polytechnic Institute, N234, The study of the ionosphere by the incoherent scatter method, Issue 4, Kharkov, 16-17, 1986 (in Russian).

Bowles, K. L.: Observations of Vertical-Incidence Scatter from the Ionosphere at $41 \mathrm{Mc} / \mathrm{sec}$, Phys. Rev. Lett., 1, 454-455, 1958.

Burmaka, V. P. and Chernogor, L. F.: Complex Diagnostics of Disturbances in the Ionospheric Plasma Parameters Far from the Trajectories of Launched Rockets, Geomagn. Aeronomy, 49, 637$652,2009$.
Burmaka, V. P. and Chernogor, L. F.: Wave Disturbances in the Ionosphere during a Lasting Solar Activity Minimum, Geomagn. Aeronomy, 52, 183-196, 2012.

Burmaka, V. P., Domnin, I. F., Uryadov, V. P., and Chernogor, L. F.: Variations in the parameters of scattered signals and the sonosphere connected with plasma modification by high-power radio waves, Radiophys. Quantum El., 52, 774-795, 2009.

Chepurnoy, Ya. N.: Incoherent scatter facility with fully steerable antenna, XVI All-Union conference on radiowave propagation, Abstracts, Kharkov, 1990 (in Russian).

Chernogor, L. F., Grigorenko, Ye. I., and Lyashenko, M. V.: Effects in the geospace during partial solar eclipses over Kharkiv, Int. J. Remote Sens., 32, 3219-3229, 2011.

Chernogor, L., Domnin, I., Emelyanov, L., Kharytonova, S., and Lyashenko, M.: Ionospheric storm effects above Kharkov during the August 5-6, 2011, EGU General Assembly 2012, Vienna, Austria, 22-27 April 2012, Geophys. Res. Abstr., 14, EGU2012630-1, 2012.

Chernyaev, S. V.: UHF system for ionospheric research, Bulletin of the Kharkov Polytechnic Institute "The study of the ionosphere by the incoherent scatter method", 1, 66-72, 1979 (in Russian).

Domnin, I. F., Emelyanov, L. Y., Pasura, S. A, Kharitonova, S. V., and Chernogor, L. F.: Dynamic processes in the ionosphere during a very moderate magnetic storm on 20-21 January 2010, Kosmichna nauka i technologiya (Space Science and Technology), 17, 26-40, 2011 (in Russian).

Domnin, I. F., Emelyanov, L. Ya., and Chernogor, L. F.: Dynamics of the ionospheric plasma above Kharkiv during the January 4, 2011 solar eclipse, Radio Physics and Radio Astronomy, 3, 311324, $2012 \mathrm{a}$.

Domnin, I. F., Panasenko, S. V., Uryadov, V. P., and Chernogor, L. F.: Results of Radiophysical Study of Wave Disturbances in the Ionospheric Plasma During Its Heating by High-Power HF Radio Transmission of "Sura" facility, Radiophys. Quantum El., 55, 253-265, 2012b.

Emelyanov, L. Ya.: Features of receiving-driving system of the incoherent scatter research facility, Proceedings of the Conference "Microwave engineering and satellite reception", Sevastopol, 6, 798-801, 1993 (in Russian).

Emelyanov, L. Ya.: Radio receiver system of the incoherent scatter radar, Bulletin of the Kharkov State Polytechnic University, Kharkov, 31, 108-112, 1999 (in Russian).

Emelyanov, L. Ya., Lyashenko, M. V., and Chernogor, L. F.: Effects in geospace plasma during the partial solar eclipse on August 1, 2008 over Kharkiv. 1. The results of observations, Kosmichna nauka i technologiya (Space Science and Technology), 15, 7081, 2009 (in Russian).

Erickson, P. J., Taran, V. I., Foster, J. C., Goncharenko, L. P., and Gonzales, S. A.: Simultaneously longitudinal and latitudinal topside light ion variations from Kharkov, Millstone Hill and Arecibo radar observations, EOS Trans. AGU, 80, Fall Meeting, F771, (SA12A-09), 1999.

Fejer, J.: Scattering of radio waves by an ionized gas in thermal equilibrium, Can. J. Phys., 38, 1114-1133, 1960.

Fejer, J.: Scattering of radio waves by an ionized gas in thermal equilibrium in the presence of uniform magnetic field, Can. J. Phys., 39, 716-740, 1961.

Golovin, V. I., Galushkin, N. N., Lazarev, V. A., and Gordeyev, A. A.: Radio transmitting system of the incoherent scatter 
research facility, Bulletin of the Kharkov Polytechnic Institute "The study of ionosphere by the incoherent scatter method", 1, 45-50, 1979a (in Russian).

Golovin, V. I., Rogozhkin, E. V., Taran, V. I., and Chernyaev, S. V.: Observations of the ionosphere using the incoherent scatter method, Bulletin of the Kharkov Polytechnic Institute "The study of ionosphere by the incoherent scatter method", 1, 12-22, 1979b (in Russian).

Goncharenko, L. P., Bogovsky, V. K., Zabirko, M. N., and Koval, A. D.: Preliminary results of artificially enhanced plasma line, Republican Interagency Scientific and Technical collection of articles "Ionosphere", Kharkov, 1, 110-113, 1991 (in Russian).

Goncharenko, L. P., Salah, J. E., van Eyken, A., Howells, V., Thayer, J. P., Taran, V. I., Shpynev, B., Zhou, Q., and Chau, J.: Observations of the April 2002 geomagnetic storm by the global network of incoherent scatter radars, Ann. Geophys., 23, 163181, doi:10.5194/angeo-23-163-2005, 2005.

Gordon, W. E.: Incoherent scattering of radio waves by free electrons, with applications to space exploration by radar, Proc. I.R.E., 46, 1824-1829, 1958.

Grigorenko, Ye. I.: Studies of the ionosphere based on the Faraday effect observations during incoherent scatter of radiowaves, collection of articles "Ionospheric studies", Moscow, Soviet Radio, N27, 60-73, 1979 (in Russian).

Grigorenko, Ye. I.: Refinement of the empirical model of the midlatitude ionosphere obtained in the Kharkov Polytechnic Institute, Republican Interagency scientific and technical collection of articles "Ionosphere", Kharkov, 1, 16-24, 1991 (in Russian).

Grigorenko, Ye. I., Bogovsky, V. K., Emelyanov, L. Ya., Kiyashko G. A., Pulyayev V. A., and Smaglo, N. A.: Variations of ionospheric parameters in periods of high and low solar activity, Geomagn. Aeronomy, 41, 199-203, 2001 (in Russian).

Grigorenko, Ye. I., Lysenko, V. N., Taran, V. I., and Chernogor, L. F.: Analysis and classification of ionospheric storms at the midlatitudes of Europe , Kosmichna nauka i technologiya (Space Science and Technology), 13, 58-96, 2007 (in Russian).

Hagfors, T.: Density fluctuation in a plasma in magnetic field with application to the ionosphere, J. Geophys. Res., 56, 1699-1712, 1961.

Hagfors, T.: Incoherent Scattering of Radio Waves as a Method of Studying the Ionosphere, in: Electron Density Profiles in the Ionosphere and Exosphere, edited by: Maehlum, B., Pergamon Press, Oxford, 337-347, 1962.

Ivanov-Kholodny, G. S., Kishcha, P. V., and Zhivolup, T. G.: A MidLatitude E-Layer Peak Height Model, Adv. Space Res., 22, 767770, 1998

Kotov, D. V. and Chernogor, L. F.: Spatial and temporal variation in the hydrogen ions fraction under various space weather conditions, Proceedings of XII Conference of Young Scientists "Interaction of fields and radiation with substance" (Irkutsk, Russia, 19-24 September 2011), Irkutsk, 202-204, 2011.

Lyashenko, M., Domnin, I., and Chernogor, L.: Development of Central Europe Regional Ionospheric Model (CERIM IION) based on Kharkov incoherent scatter data, Workshop on Assessment and Validation of Space Weather Models (Alcala de Henares, Spain, 16-17 March 2011), 23-24, 2011.
Lysenko, V. N.: Features of correlation processing incoherent scatter signal by sounding the ionosphere in the VHF band with the radio pulses of $800 \mu$ s duration, Bulletin of the Kharkov State Polytechnic University, Kharkov, 31, 90-95, 1999 (in Russian).

Lysenko, V. N.: Measuring ionospheric parameters using the methods of correlation processing of incoherent scatter signal, Radiofizika i elektronika (Radio Physics and Electronics), Kharkov, Institute of Radio Physics and Electronics, National Academy of Sciences of Ukraine, 7, 82-88, 2002 (in Russian).

Lysenko, V. N. and Kochergin, A. G.: Measurements of the ionospheric parameters using processing equipment on digital processors, XVII Conference on Radio Wave Propagation, Abstracts, Ulyanovsk, 21-24 September 1993 (in Russian).

Lysenko, V. N., Kononenko, A. F., and Chernyak, Yu. V.: Programmable correlator to measure the ionospheric parameters using the incoherent scatter method, Bulletin of National Technical University "Kharkov Polytechnic Institute", Special Issue "Radiophysics and ionosphere", Kharkov, NTU "KhPI", N23, 4962, 2004.

Maglevanny, N. P., Taran, V. I., Gordeyev, A. A., and Sklyarov, I. B.: Application wideband sounding signals for measurement of ionospheric parameters, collection of articles "Ionospheric studies”, Moscow, Soviet Radio, N27, 92-97, 1979 (in Russian).

Mishin, E. V., Foster, J. C., Potekhin, A. P., Rich, F. J., Schlegel, K., Yumoto, K., Taran, V. I., Ruohoniemi J. M., and Friedel, R.: Global ULF disturbances during a stormtime substorm on 25 September 1998, J. Geophys. Res., 107, 1486, doi:10.1029/2002JA009302, 2002.

Pulyaev, V. A., Dzyubanov, D. A., and Domnin, I. F.: Determination of the ionospheric parameters using the incoherent scattering technique, Monograph, Kharkiv, NTU “KPI”, 240 pp., 2011 (in Russian).

Rogozhkin, E. V.: Measuring the ionospheric plasma parameters using the correlation function of incoherent scatter signal, collection of articles "Ionospheric studies", Moscow, Soviet Radio, N27, 46-59, 1979 (in Russian).

Rogozhkin, E. V., Zabirko, M. N., Paun, M. N., and Shatalova, N. F.: The correlator of experimental facility of the Kharkov Polytechnic Institute, Bulletin of the Kharkov Polytechnic Institute "The study of ionosphere by the incoherent scatter method", 1, 40-44, 1979 (in Russian).

Rogozhkin, E. V, Bogovsky, V. K., Smirnov, A. N., and Gershtein, L. Ya.: Preliminary results of investigation of the HFheating effect on the ionosphere, Bulletin of the Kharkov Polytechnic Institute "The study of ionosphere by the incoherent scatter method", Kharkov, 5, 47-49, 1987 (in Russian).

Rogozhkin, E. V., Pulyaev, V. A., and Khlebnikov,A.N.: System for incoherent scatter signal processing, Bulletin of the Kharkov Polytechnic Institute "The study of ionosphere by the incoherent scatter method", 7, 24-30, 1989 (in Russian).

Taran, V. I.: The incoherent scatter experimental facility of the Kharkov Polytechnic Institute, Radiotekhnika i elektronika (Radio Engineering and Electronics), XXI, 1-10, 1976 (in Russian).

Taran, V. I.: A study of the natural and artificially disturbed ionosphere by the incoherent scatter method, Geomagn. Aeronomy, 41, 659-666, 2001 (in Russian).

Taran, V. I. and Grigorenko, Ye. I.: Hydrogen ion study with incoherent scatter method. 1. Comparison of results obtained at Kharkov, Arecibo and Millstone Hill radars, X Joint International 
Symposium "Atmospheric and Ocean Optics. Atmospheric Physics", Tomsk, 2-5 July 2002, D3-17, 2002a.

Taran, V. I. and Grigorenko, Ye. I.: Hydrogen ion study with incoherent scatter method. 2. Comparison of results obtained at Kharkov IS radar, Atmosphere Explorer and model, X Joint International Symposium "Atmospheric and Ocean Optics. Atmospheric Physics”, Tomsk, 2-5 July 2002, D3-18, 2002 b.

Taran, V. I., Podyachy, Yu. I., Smirnov, A. N., and Gershtein, L. Ya.: Ionospheric disturbances after the powerful surface explosion from incoherent scatter observations, Proceedings of the USSR Academy of Sciences "Physics of the Earth", Moscow, N11, 7579, 1985 (in Russian).

Taran, V. I., Goncharenko, L. P., Bogovsky, V. K., and Lysenko, V. N.: Changes of the electron temperature and concentration of the ionospheric F-region under the influence of highpower radiowaves, Geomagn. Aeronomy, 33, 98-104, 1993 (in Russian).
Taran, V. I., Bogovsky, V. K., Lysenko, V. N., Grigorenko, Ye. I., and Emelyanov, L. Ya.: Investigation of circumterrestrial space by means of incoherent scatter radar // Kosmichna nauka i technologiya (Space Science and Technology), Space Plasma Physics (supplement to the journal), Kyiv, 7, 36-41, 2001.

"Theory and Practice of Application of the Incoherent Scatter of Radio Waves Method", All-USSR Scientific and Technical Conference, Kharkov, 24-26 May 1983, Book of Abstracts, 134 pp., 1983.

"Theory and Practice of the Incoherent Scatter Method Application to Study the Ionosphere", All-USSR Conference, Kharkov, 2-4 July 1987, Book of Abstracts, 100 pp., 1987.

The 16th All-USSR Conference on Propagation of Radio Waves, Book of Abstracts, Part 1, Kharkov, 308 pp., 1990.

Yemelyanov, L. Ya. and Dzyubanov, D. A.: The Peculiarities of Mid-Latitude Ionosphere Plasma Drift Velocity Determination, Telecommunications Radio Engineering, 66, 1313-1327, 2007. 